\title{
ĐẶC ĐIỂM SUY GIẢM CHỨC NĂNG TRÍ NHỚ TRÊN BỆNH NHÂN ĐộNG KINH TRƯỞNG THÀNH TẠI BỆNH VIÊ̂N BẠCH MAI
}

\section{TÓM TẮT}

Bệnh động kinh gây hậu quả là cơn động kinh và có thể gây tổn thương các chức năng cao cấp của não trong đó có chức năng trí nhớ. Điều này dẫn đến suy giảm chất lượng cuộc sống đối với bệnh nhân động kinh. Mục tiêu: Mô tả đặc điểm lâm sàng suy giảm chức năng trí nhớ trên bệnh nhân động kinh trưởng thành. Đối tượng và phương pháp: Nghiên cứu mô tả cắt ngang trên 144 bệnh nhân được chẩn đoán động kinh theo tiêu chuẩn của Liên hội chống động kinh quốc tế (International League Against Epilepsy) tại bệnh viện Bạch Mai từ tháng 07 năm 2020 đến tháng 07 năm 2021. Kết quả: Có 78 bệnh nhân nam và 66 bệnh nhân nữ với độ tuổi trung bình là 44,2 \pm 9,1.Độ tuổi khởi cơn động kinh lần đầu hay gặp nhất ở nhóm dưới 18 tuổi, sau 60 tuổi thì tỷ lể này cũng có xu hướng tăng lên. Trong nhóm bệnh nhân nghiên cứu, bênh nhân xuất hiện cơn động kinh cuc bộ đơn thuần là nhiều nhất $(38,9 \%$, ), số lượng bệnh nhân xuất hiên cớn cuc bô phức hợp ít nhất $(11,1 \%)$. Tỷ lệ bệnh nhân động kinh bị suy giảm trí nhớ là 34,0\%, trong đó nam giới chiếm 33,3\%, nữ giới chiếm 34,8\%, không có sự khác biệt về tî lệ suy giảm trí nhớ ở 2 giới.Bênh nhân có tân suất cợn động kinh dày tỷ lệ bi suy giảm trí nhớ là $58,3 \%$, bệnh nhẩn bị bệnh kéo dài trên 5 năm tỷ lệ suy giảm trí nhớ là $55,8 \%$. Kết luận: Trong nghiên cứu của chúng tôi, bệnh nhân động kinh có tỷ lệ suy giảm trí nhớ tương đối cao, chiếm 34,0\%. Bệnh nhân có thời gian mắc bệnh càng lâu, tân suất xuất hiện cớn động kinh càng dày thì tỷ lệ suy giảm trí nhớ càng cao, vì vậy cần có sự can thiệp điêuu trị tích cực hơn ở nhóm này.

Tư khóa: Bệnh động kinh, cơn động kinh, chức năng trí nhớ.

\section{SUMMARY \\ CHARACTERISTICS IMPAIRMENT MEMORY OF MATURE EPILEPSY PATIENTS AT BACH MAI HOSPITAL}

Epilepsy leads to seizures and can impair advanced brain functions including memory function. This leads to a decrease in the quality of life for epilepsy patients. Objective: Describe clinical features of impaired memory function in mature epilepsy patients. Subjects and methods: Cross-sectional descriptive study on 144 patients diagnosed with epilepsy according to the International League Against Epilepsy (International League Against Epilepsy) criteria at Bach Mai hospital from July 2020 to July 2021.

${ }^{1}$ Trường Đai hoc Y Hà Nôi

Chịu trách nhiệm chính: Chử Văn Dũng

Email: chuvandunghmu@gmail.com

Ngày nhận bài: 2.8.2021

Ngày phản biện khoa học: 30.9.2021

Ngày duyệt bài: 7.10.2021

\section{Chử Văn Dũng ${ }^{1}$, Nguyễn Văn Hướng ${ }^{1}$}

Results: There were 78 male patients and 66 female patients with an average age of 44,2 $\pm 9,1$. The age of first seizure onset was most common in the group under 18 years of age, after 60 years of age, the rate of first seizure appearedalso tends to increase.In this study, patients had the most simple partial seizures $(38,9 \%)$, the number of patients with complex partial seizures was the least $(11,1 \%)$. The proportion of epilepsy patients with memory impairment was $34,0 \%$, of which men accounted for $33,3 \%$, women accounted for $34,8 \%$, there was no difference in the rate of memory impairment in the two sexes. Patients with a frequency of thick seizures have memory impairment rate of $58,3 \%$, patients with disease lasting more than 5 years, the rate of memory loss is $55,8 \%$. Conclusions:In our study, epilepsy patients had a relatively high rate of memory impairment, accounting for $34,0 \%$. The longer the patient has a disease, the higher the frequency of seizures, the higher the rate of memory loss, so there is a need for more active treatment intervention in this group.

Keywords: Epilepsy, seizure, memory function.

\section{I. ĐĂT VẤN ĐỀ}

Động kinh là một bệnh lý mạn tính của não, có tỷ lệ mắc tương đối cao,tỷ lệ mắc bệnh động kinh ước tính chung trong suốt cuộc đời là 7,60 trên 1.000 dân [1]. Bệnh động kinh gây hậu quả là cơn động kinh và có thể gây tổn thương các chức năng cao cấp của não trong đó có chức năng trí nhớ. Tùy thuộc vào mức độ nặng của rối loạn trí nhớ mà gây ảnh hưởng đến các hoạt động chức năng trong cuộc sống hằng ngày của bệnh nhân khiến bệnh nhân phải phụ thuộc một phần hoăc hoàn toàn vào người thân. Cùng với các nghiển cứu rối loạn trí nhớ liên quan đến các bênh lý như Alzheimer, tai biến mạch máu não, viêm não rối loạn trí nhớ trên bệnh nhân động kinh nên được quan tâm để từ đó giúp cho việc đưa ra các biện pháp phù hợp trong điều trị cũng như trong chằm sóc bênh nhân động kinh nhằm cải thiện chất lượng cuộc sống của người bệnh.

Xuẩt phát từ các lý do nêu trên, chúng tôi tiến hành đề tài: "đặc điểm suy giảm chức năng trí nhớ trên bệnh nhân động kinh trưởng thành tại bệnh viện bạch mai" với mục tiêu mô tả đặc điểm lâm sáng rối loạn chức năng trí nhớ trển bệnh nhân động kinh trưởng thành.

\section{II. ĐỐI TƯợNG VÀ PHƯƠNG PHÁP NGHIÊN CỨU}

2.1. Đối tượng nghiên cứu. Gồm 144 bệnh nhân nội trú của bệnh viện Bạch Mai được chẩn đoán động kinh từ tháng 07 năm 2020 đến 
tháng 07 năm 2021.

2.2. Tiêu chuẩn lựa chọn. Bệnh nhân từ 18 tuổi trở lên đã được chẩn đoán là động kinh theo tiêu chuẩn của của Liên hội chống động kinh quốc tế (International League Ágainst Epilepsy [2]).

\subsection{Tiêu chuẩn loại trừ}

- Bệnh nhân có các bệnh lý như Alzheimer hoặc sa sút trí tuệ do nguyên nhân khác, bệnh tâm thần phân liệt, tiền sử nghiện rượu, sử dụng ma túy trước khi có cơn động kinh đầu tiên.

- Bệnh nhân chậm phát triển tâm thần vận động từ nhỏ (trước 03 tuổi).

- Bệnh nhân không đồng ý tham gia nghiên cứu.

2.4. Phương pháp nghiên cứu. Mô tả cắt ngang.

2.5. Kỹ thuật và công cụ thu thập thông tin. Bệnh nhân được thăm khám, hỏi bệnh theo mẫu bệnh án nghiên cứu gồm các mục khám nội khoa tổng quát, khám thần kinh, phân loại cợn động kinh theo phân loại quốc tế 1981, thực hiện một số trắc nghiệm trí nhớ bao gồm: trắc nghiệm học từ của California (California Verbal Learning Test/ CVLT), trắc nghiệm trí nhớ logic của thang điểm trí nhớ Wechsler (WMS-III, 1997), tiểu nhóm trắc nghiệm mô phỏng thị giác của WMS-III và Trắc nghiệm vẽ hình phức tạp của Rey-Osterreitht (Visser, 1985).

2.6. Phương pháp thống kê và xử lý số liệu. Theo chương trình SPSS 22.0.

\section{KẾT QUẢ NGHIÊN CứU}

\section{1 Đặc điểm chung của đối tượng nghiên cứu}

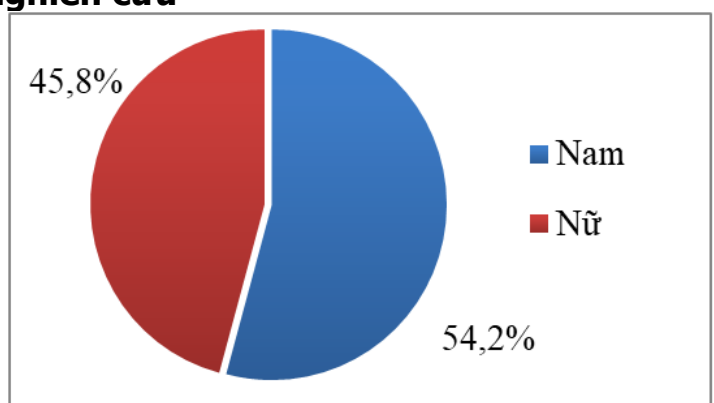

Biểu đồ 3. 1 Phân bố theo giới

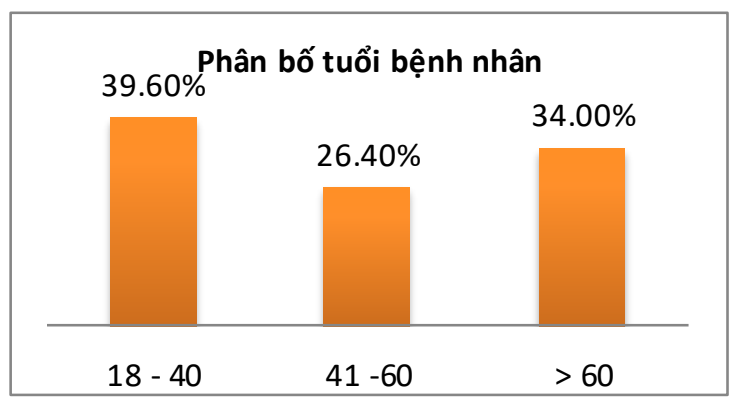

Biểu đồ 3. 2 Phân bố theo tuổi

Nhânn xét: Trong nhóm bệnh nhân nghiên cứu, bao gồm 78 bệnh nhân nam và 66 bệnh nhân nữ, với tỉ lệ nam, nữ lần lượt là $54,2 \%$ và 45,8\%. Trong 144 bệnh nhân, bệnh nhân thấp tuổi nhất là 18 tuổi, cao tuổi nhất là 81 tuổi. Tuổi trung bình của nhóm nghiên cứu là 44,2 $\pm 9,1$.

Bảng 3. 3 Đặc điểm bệnh động kinh của nhóm nghiên cứu

\begin{tabular}{|c|c|c|c|}
\hline Đặc điểm bệnh động kinh & Số bệnh nhân (n) & Tỷ lệ (\%) \\
\hline \multirow{4}{*}{ Tuổi khởi phát } & $<6$ tuối & 35 & $24,3 \%$ \\
\cline { 2 - 4 } & $6-18$ tuối & 36 & $25,0 \%$ \\
\cline { 2 - 4 } & $18-40$ tuối & 21 & $14,6 \%$ \\
\cline { 2 - 4 } & $40-60$ tuổi & 18 & $12,5 \%$ \\
\cline { 2 - 4 } & $>60$ tuối & 34 & $23,6 \%$ \\
\hline \multirow{4}{*}{ Thể loại cơn động kinh } & Cơn toàn thể & 35 & $24,3 \%$ \\
\cline { 2 - 4 } & Cơn cục bộ đơn thuần & 56 & $38,9 \%$ \\
\cline { 2 - 4 } & Cơn cục bộ toàn thể hóa & 37 & $25,7 \%$ \\
\cline { 2 - 4 } & Cơn cục bộ phức hợp & 16 & $11,1 \%$ \\
\hline
\end{tabular}

Nhân xét: Trong nhóm bênh nhân nghiên cứu, nhóm tuổi khởi phát từ dưới 1 tuổi tuổi thường gặp nhất, chiếm 49,3\%. Bệnh nhân khởi phát sớm nhất là 2 tuổi, muộn nhất là 78 tuổi, và độ tuổi khởi phát trung bình là 43,8 $\pm 5,0$ tuổi, không có sự khác biệt về tuổi khởi phát trung bình giữa 2 giới. Tỉ lệ bệnh nhân có cơn động kinh cục bộ đơn thuần cao hởn so với các loại cơn khác, cơn cục bộ phức hợp chiếm tỉ lệ thấp nhất $(11,1 \%)$.

3.2. Đặc điểm lâm sàng rối loạn chức năng trí nhớ

Bảng 3.2 Tỉ lệ bệnh nhân suy giảm trí nhớ theo giới

\begin{tabular}{|c|c|c|c|}
\hline & Nam & Nũ̃ & Tống \\
\hline Có suy giảm trí nhớ & $26(33,3 \%)$ & $23(34,8 \%)$ & $49(34,0 \%)$ \\
\hline Không suy giảm trí nhó & $52(66,7 \%)$ & $43(65,2 \%)$ & $95(66,0 \%)$ \\
\hline & $78(54,2 \%)$ & $66(45,8 \%)$ & $144(100 \%)$ \\
\hline
\end{tabular}


Nhận xét: Tỉ lệ bệnh nhân động kinh có suy giảm trí nhớ là 34,0\%, trong đó nam giới chiềm $33,3 \%$, nữ giới chiểm $34,8 \%$, không có sự khác biệt về tỉ lệ suy giảm trí nhớ ở 2 giới.

Bảng 3.3 Liên quan giứa tần suât cớn động kinh với suy giảm trí nhớ

\begin{tabular}{|c|c|c|c|c|}
\hline & $\begin{array}{c}\text { Tân suất cơn } \\
\text { thưa }\end{array}$ & $\begin{array}{c}\text { Tân suất cơn } \\
\text { trung bình }\end{array}$ & $\begin{array}{c}\text { Tân suất cơn } \\
\text { dày }\end{array}$ & Tổng \\
\hline Có suy giảm trí nhớ & $16(23,9 \%)$ & $19(35,8 \%)$ & $14(58,3 \%)$ & $49(34,0 \%)$ \\
\hline Không suy giảm trí nhớ & $51(76,1 \%)$ & $34(64,2 \%)$ & $10(41,7 \%)$ & $95(66,0 \%)$ \\
\hline & $67(46,5 \%)$ & $53(36,8 \%)$ & $24(16,7 \%)$ & $144(100 \%)$ \\
\hline
\end{tabular}

Nhận xét: Bệnh nhân có tần suất cơn động kinh dày chiểm tỉ lệ thấp $(16,7 \%)$ tuy nhiên tỉ lệ bị suy giảm trí nhớ của nhóm này là rất cao $(58,3 \%)$, hơn hẳn 2 nhóm tần suất cơn trung bình $(35,8 \%)$ và thưa $(23,9 \%)$.

Bảng 3.4 Liên quan giữa thời gian mắc bệnh với suy giảm trí nhớ

\begin{tabular}{|c|c|c|c|c|}
\hline & < 1 năm & $\mathbf{1 ~ - ~ 5 ~ n a ̆ m ~}$ & > 5 năm & Tống \\
\hline Có suy giảm trí nhớ & $5(17.9 \%)$ & $20(27,4 \%)$ & $24(55,8 \%)$ & $49(34,0 \%)$ \\
\hline Không suy giảm trí nhớ & $23(81,1 \%)$ & $53(72,6 \%)$ & $19(44,2 \%)$ & $95(66,0 \%)$ \\
\hline & $28(19,4 \%)$ & $73(50,7 \%)$ & $43(29,9 \%)$ & $144(100 \%)$ \\
\hline
\end{tabular}

Nhận xét: Bệnh nhân có thời gian mắc bệnh trên 5 năm có $55,8 \%$ bị suy giảm trí nhớ, với nhóm thời gian mắc bệnh dưới 1 năm và từ 1 đến 5 năm tỉ lệ suy giảm trí nhớ lần lượt là $17,9 \%$ và $27,4 \%$.

\section{BÀN LUẬN}

4.1. Đặc điểm chung của đối tượng nghiên cứu. Trong nghiên cứu trên 144 bệnh nhân của chúng tôi, có 78 bệnh nhân nam và 66 bệnh nhân nữ, tỉ lệ nam/nữ tương ứng là 1/0,85. Kết quả này khác với kết quả của Lê Thế Phi năm năm 2018 [3], sự khác biệt có thể là do khác nhau về quần thể nghiên cứu.

Trong nghiên cứu này, tuổi trung bình của bệnh nhân là 44,2 $\pm 9,1$. Tỷ lệ số bệnh nhân ở các nhóm tuổi gần tương đương nhau, nhóm chiếm tỷ lệ cao nhất là nhóm từ 18 đến 40 tuổi $(39,6 \%)$. Nghiên cứu của Hồ Anh Thủy trên bệnh nhân động kinh trưởng thành năm 2011 [4]cũng cho thây kết quả tượng tự về tuổi trung

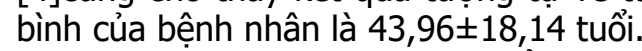

Nghiên cứu này cho thấy tuổi khởi phát cơn động kinh lần đầu xuất hiện ở bất kỳ nhóm tuổi nào, khởi phát sớm nhất là 2 tuổi, muộn nhất là 78 tuổi, tuy nhiên tỷ lệ khởi phát cơn ở nhóm dưới 18 tuổi là hay gặp nhất (49,3\%), các nhóm khác chiếm tỷ lệ tương đối thấp.Có sự tăng tỷ lệ ở nhóm bệnh nhân khởi phát cơn động kinh lần đầu trên 60 tuổi $(23,6 \%)$. Kết quả này cũng phù hợp với kết quả nghiên cứu của Beghi và cộng sự [5] và nhiêuu tác giả khác trên thế giới, điều này được giải thích do nhóm người cao tuối tăng cao nguy cơ mắc các bệnh lý mạch máu não và từ đó có thể gây xuất hiện cơn động kinh.

Bệnh nhân xuất hiện cơn động kinh cục bộ đơn thuần chiếm tỷ lệ cao nhất $(38,9 \%)$, trong khi đó bệnh nhân xuất hiện cơn động cục bộ phức hợp chỉ chiếm $11,1 \%$, kết quả này cũng tương tự như kết quả nghiên cứu của Kotsopoulos và cộng sự [6].
4.2. Đặc điểm suy giảm trí nhớ trên bệnh nhẩn động kinh. Trong nghiên cứu của chúng tôi, tỷ lệ bệnh nhân động kinh bị suy giảm trí nhớ là $34,0 \%$, trong đó tỷ lệ nam giới là $33,3 \%$, nữ giới là $34,8 \%$, không có sự khác biệt về tỷ lệ suy giảm trí nhớ ở 2 giới. Nghiên cứu củaMarques $C M$ và cộng sự trên 61 bệnh nhân động kinh [7] cho thấy có $66 \%$ bệnh nhân bị rối loạn trí nhớ cao hơn tỷ lệ của chúng tôi tương đổi nhiều. Tuy nhiên do nghiên cứu của Marques tập trung vào bệnh nhân động kinh thùy thái dương, một cấu trúc của não tham gia trực tiếp vào cơ chế hình thành và lưu trữ trí nhớ nên tỷ lệ suy giảm trí nhớ trong nghiên cứu này cao hơn hằn. Từ đây cho thấy bệnh động kinh gây suy giảm trí nhớ tương đối nhiều, cần có sự can thiệp nhất định để cải thiện tỷ lệ này.

Bệnh nhân có tần suất cớn động kinh dày chiểm tỉ lệ thấp $(16,7 \%)$ tuy nhiên tî̉ lệ bị suy giảm trí nhớ của nhóm này là rất cao $(58,3 \%)$, hơn hẳn 2 nhóm tần suất cơn trung bình $(35,8 \%)$ và thưa $(23,9 \%)$. So với kết quả nghiên cứu của Wang và cộng sự năm 2019 [8] cũng cho thấy tần suốt cơn động kinh có tương quan nghịch chiêu với chức năng trí nhớ. Như vậy cơn động kinh càng khó kiểm soát thì càng gâyy suy giảm chức năng trí nhớ nghiêm trọng.

Ngoài ra, thời gian mắc bệnh động kinh cũng cho thây kết quả như vậy. Nghiên cứu chúng tôi tỷ lệ bệnh nhân mắc bệnh từ 1 đến 5 năm chiếm hơn một nửa $(50,7 \%$. Tuy nhiên vẫn có 43 bệnh nhân mắc bệnh trên 5 năm, trong đó 29 người $(55,8 \%)$ bị suy giảm trí nhớ, tỷ lệ này cao hơn ở các nhóm thời gian mắc bệnh từ 1 đến 5 năm $(27,4 \%)$ và nhóm thời gian mắc bệnh dưới 1 
năm $(17,9 \%)$. Kent và cộng sự [9] đã cho thấy những bệnh nhân động kinh trong thời gian dài tỉ lệ bị suy giảm trí nhớ cao hơn cũng như điểm số trong các thang điểm đánh giá chức năng trí nhớ cũng thấp hơn. Cả tần suất xuất hiện cớn và thời gian mắc bệnh đều có liên quan tới chức năng trí nhớ. Tần suất cơn càng dày, thời gian mắc bệnh càng lâu thì chức năng cao cấp của não càng dễ bị ảnh hưởng gây suy giảm chức năng trí nhớ, rõ ràng cần có sự can thiệp điều trị tích cực với bệnh nhân động kinh để giảm thiểu ảnh hưởng xấu lên cuộc sống của họ.

\section{KẾT LUÂ̂N}

Bệnh động kinh là bệnh lý mạn tính của não với tỉ lệ mắc tương đối cao. Bệnh ngoài gây xuất hiện cởn động kinh còn gây ảnh hưởng đên chức năng cao cấp của não, trong đó có gây suy giảm trí nhớ, làm giảm chất lượng cuộc sống của người bệnh. Nhiều yếu tố của bệnh động kinh của liên quan đến suy giảm trí nhớ, đặc biệt là tần suất xuất hiện cơn và thời gian mắc bệnh. Do đó cần có sự quan tâm lớn hơn từ các bác sĩ lâm sàng, góp phần xây dựng chiến lược chăm sóc và điều trị tốt hơn cho bệnh nhân.

\section{TÀl LIẸU THAM KHẢO}

1. Fisher R.S., van Emde Boas W., Blume W. và cộng sự. (2005). Epileptic seizures and epilepsy: definitions proposed by the International League Against Epilepsy (ILAE) and the International Bureau for Epilepsy (IBE). Epilepsia, 46(4), 470-472.

2. Fisher R.S., Acevedo C., Arzimanoglou A. và cộng sự. (2014). ILAE official report: a practical clinical definition of epilepsy. Epilepsia, 55(4), 475-482.

3. Lê Thế Phi (2018), Đánh giá ảnh hưởng của thuốc phenobarbital lến chức năng nhận thức trên bênh nhân trưởng thành mắc đông kỉnh cơn lớn. Luận văn Thạc sĩ Y học, Trường Đại học Y Hà Nội.

4. Hồ Anh Thủy (2011), Nghiên cứu môt số đặc điểm về rối loạn nhận thức trên bệnh nhân đông kinh người trưởng thành được điều trị bắng phenobarbital. Luận văn tốt nghiệp Bác sỹ chuyên khoa cấp II, Trường Đại học Y Hà Nội, Hà Nội.

5. Beghi E. (2020). The Epidemiology of Epilepsy. NED, 54(2), 185-191.

6. Kotsopoulos I., de Krom M., Kessels F. và cộng sự. (2005). Incidence of epilepsy and predictive factors of epileptic and non-epileptic seizures. Seizure, 14(3), 175-182.

7. Marques C.M., Caboclo L.O.S.F., da Silva T.I. và cộng sự. (2007). Cognitive decline in temporal lobe epilepsy due to unilateral hippocampal sclerosis. Epilepsy Behav, 10(3), 477-485.

8. Wang L., Chen S., Liu C. và cộng sứ. (2019). Factors for cognitive impairment in adult epileptic patients. Brain Behav, 10(1), e01475.

9. Kent G.P., Schefft B.K., Howe S.R. và cộng sự. (2006). The effects of duration of intractable epilepsy on memory function. Epilepsy Behav $9(3), 469-477$.

\section{SỬ DƯNG TÍNH TOÁN DFT KẾT HỢP VỚI THỰC NGHIỆM ĐỂ XÁC ĐINH CÁC ĐĂC TÍNH CỦA BENZOYL PEROXID}

\section{TÓM TẮT}

Hoạt chất benzoyl peroxid được sử dụng bôi ngoài da để điều trị mụn trứng cá, tiêu sừng và chống viêm. Kết quả quang phổ Raman, IR thu được từ thực nghiệm được so sánh với các tính toán lượng tử Gaussian với DFT/B3LYP kết hớp với các tiêu chuẩn 6$311+G(d, p)$. Các đặc tính lý hóa và đặc tính dược lực của phân tử hữu cơ benzoyl peroxide đã được phẩn tích bằng quang phổ IR, Raman. Vị trí số sóng đặc trưng của các liên kết, các nhóm trong benzoyl peroxid đều bị lệch nhiêu so với vị trí dải bước sóng thông thường. Phân tích điện Mulliken cho thấy các đám mây điện tử dẫn hướng qua carbon liên kết với

*Trường Đại học Dược Hà Nội

Chịu trách nhiệm chính: Nguyễn Đức Thiện

Email: thiennd@hup.edu.vn

Ngày nhân bài: 3.8.2021

Ngày phản biện khoa học: 29.9.2021

Ngày duyệt bài: 6.10.2021

\section{Nguyễn Đức Thiện*, Nguyễn Thị Mỹ Linh*,} Lê Thị Phương Anh*, Điêu Diễm Quỳnh*

nhóm peroxide của phân tử trên cùng của vòng benzen. Độ âm điện và thế hóa học của benzoyl peroxide có cùng đồ lớn là 4,72955 , cho các liên kết hóa học chặt chẽ và độ bền liên kết của electron cao.

Tư khóa: benzoyl peroxide, phổ Raman, phổ IR, phân bố điện tích Mulliken, DFT.

\section{SUMMARY \\ USING DFT CALCULATIONS COMBINED WITH EXPERIMENTAL DATA TO DETERMINE THE CHARACTERISTICS OF BENZOYL PEROXIDE}

The compound benzoyl peroxide is used topically to treat acne, keratosis, and anti-inflammatory. The results of Raman and IR spectroscopy obtained in the experiment were compared with the Gaussian quantum calculations with DFT/B3LYP the basis sets $6-311 G+(d, p)$. The pharmacodynamic activity of the organic molecule benzoyl peroxide was analyzed by IR, Raman spectroscopy. The wavenumber positions of the bond in the benzoyl peroxide are all deviated from below the usual wavelength range. Mulliken 